\title{
DA CAPACIDADE DAS PESSOAS COM DEFICIÊNCIA INTELECTUAL À LUZ DA VULNERABILIDADE SOCIAL E O INSTITUTO DA TOMADA DE DECISÃO APOIADA
}

\author{
THE CAPACITY OF PEOPLE WITH INTELLECTUAL DISABILITY AT \\ THE LIGHT OF SOCIAL VULNERABILITY AND THE ESTABLISHMENT \\ OF THE SUPPORTED DECISION-MAKING
}

\author{
${ }^{1}$ Mariana Paiva Frizzera \\ ${ }^{2}$ Cristina Grobério Pazó
}

\section{RESUMO}

O presente artigo busca analisar os impactos jurídicos e sociais da ratificação pelo Brasil da Convenção sobre os Direitos das Pessoas com Deficiência e a sua posterior regulamentação pela Lei 13.146/2015. Esses diplomas legais inovaram o ordenamento jurídico ao estabelecer que as pessoas com deficiência possuem capacidade legal nas mesmas condições das demais e, em razão disso, a teoria das incapacidades do Código Civil foi substancialmente alterada. Assim, investiga-se o reflexo do reconhecimento da capacidade das pessoas com deficiência intelectual à luz da vulnerabilidade social e o novo instrumento destinado à sua proteção: a tomada de decisão apoiada.

Palavras-chave: Estatuto da Pessoa com Deficiência. Deficiência Intelectual. Capacidade civil. Vulnerabilidade social. Tomada de decisão apoiada.

\begin{abstract}
This paper analyzes the juridic and social impacts of ratification by Brazil of the Convention on the Rights or Persons with Disabilities and later its regulamentation through law 13.146/2015. These legal certifications innovated the juridical order by establishing that people with disability have legal capacity in the same conditions as the other ones and, because of this, the theory of disabilities in the Civil Code was substantially altereted. So, it is investigated the reflex of recognition of the intelectual disability at the light of social vulnerability and the new instrument destineted to their protection: the supported decision-making.
\end{abstract}

Keywords: Statute of People with Disability. Intellectual disability. Civil capacity. Social vulnerability. Supported decision-making.

\footnotetext{
${ }_{1}$ Mestranda em Direitos e Garantias Fundamentais pela Faculdades Integradas de Vitória (FDV), Vitória, Espírito Santo, Brasil. Integrante pelo Grupo de Pesquisa Direito, Sociedade e Cultura pela Faculdades Integradas de Vitória (FDV), Vitória, Espírito Santo, Brasil. Email: mari_frizzera@hotmail.com

${ }^{2}$ Doutor em Direito pela Universidade Gama Filho (UGF), Rio de Janeiro, Brasil. Docente pela Faculdade Estácio de Sá de Vitória, Espírito Santo, Brasil. Email: tutortreinamento@gmail.com
} 


\section{INTRODUÇÃO}

É importante observar que a interdição das pessoas incapazes é um dos procedimentos mais antigos do direito processual civil. Trata-se de um instituto de direito assistencial, a fim de proteger os interesses das pessoas maiores incapazes. A partir disso, é possível perceber que esse tema envolve tantos outros de forma implícita, tais como: liberdade, cidadania, direitos humanos, autonomia, estigmatização, exclusão social, doença, vulnerabilidade.

Esse instituto sempre teve como propósito retirar a capacidade das pessoas, substituindo a sua vontade pela vontade do curador, servindo apenas para a proteção dos interesses patrimoniais do incapaz, inviabilizando, assim, o pleno exercício dos seus direitos personalíssimos. As legislações responsáveis por regular o sistema de incapacidades eram pouco flexíveis em relação às características específicas dos indivíduos submetidos a elas. Por tais razões, a Convenção sobre os Direitos das Pessoas com Deficiência foi de fundamental importância para o reconhecimento dos deficientes intelectuais enquanto sujeito de direitos.

Entretanto, poucos direitos previstos na Convenção foram efetivados pelo Brasil, havendo a necessidade, então, de elaborar uma lei infraconstitucional a fim de regulamentá-la. Desse modo, a Lei 13.146/2015 (Estatuto da Pessoa com Deficiência) tem como base a Convenção sobre os Direitos das Pessoas com Deficiência, sendo que muitas conquistas tidas como inéditas, já haviam sido incorporadas ao ordenamento jurídico brasileiro por meio de uma norma de hierarquia superior.

Assim, é pertinente questionar como compatibilizar a proteção jurídica das pessoas com deficiência intelectual com o reconhecimento da sua capacidade plena?

A fim de responder essa indagação, a presente pesquisa foi dividida em três capítulos. No primeiro, será traçado um histórico do tratamento jurídico conferido aos deficientes intelectuais no Brasil, com o objetivo de analisar os principais documentos que regulamentam os direitos das pessoas com deficiência. No segundo, será analisada a teoria das incapacidades à luz da redação original do Código Civil de 2002 e da alteração promovida pela Lei 13.146/2015, tendo como base a ideia de que as pessoas com deficiência podem exercer a sua capacidade em igualdade de condições com as demais. Por fim, será abordado o instituto da tomada de decisão apoiada que representa uma grande inovação no direito brasileiro, com base na teoria da vulnerabilidade social. 
O artigo utilizou a pesquisa bibliográfica e documental para abordar o tema tratado, valendo-se do método dialético, a fim de apontar as contradições existentes entre a realidade histórica brasileira de retirada da capacidade das pessoas com deficiência intelectual e os princípios que orientam a Constituição Federal, a Convenção sobre os Direitos das Pessoas com Deficiência e a Lei 13.146/2015.

Portanto, o objetivo da presente pesquisa é analisar a situação das pessoas com deficiência intelectual, enquanto sujeitos que são vulneráveis, demandando uma maior proteção do ordenamento jurídico, sem que seja desconsiderada a sua manifestação de vontade. Constata-se que há problemas no tratamento conferido às pessoas com deficiência ao longo dos anos, cujos direitos existenciais sempre foram relegados a um segundo plano.

\section{NORMAS QUE REGULAMENTAM A SITUAÇÃO DOS DEFICIENTES INTELECTUAIS NO BRASIL CONTEMPORÂNEO}

O Código Civil de 1916 foi influenciado pelo liberalismo econômico que predominava naquele contexto histórico e, portanto, tinha caráter eminentemente individualista e patrimonialista. Desse modo, "a propriedade privada e a liberdade contratual chegaram a merecer uma tutela absoluta, sem qualquer possibilidade de relativização" (FARIAS; ROSENVALD, 2010, p. 19-20). Por esse motivo, o instituto jurídico da curatela tinha como cerne a proteção do patrimônio do incapaz e não da pessoa humana (SANTOS, 2013, p. 150). Além disso, ressalta-se que o interditado praticamente perdia a sua capacidade de agir e a sua vontade era substituída pelo arbítrio do curador, o qual nem sempre levava em consideração os interesses daquele (MENEZES; CORREIA NETO, 2014, p. 371-372).

É imperioso acentuar que o grau de deficiência e a natureza do ato praticado não eram considerados no momento de fixação da interdição, ou seja, ainda que o deficiente intelectual tivesse um mínimo de discernimento para a prática de algum ato da vida civil, a ação não poderia ser considerada de forma isolada (MEDEIROS, 2006, p. 12). Assim, cumpre salientar que Pontes de Miranda (2000, p. 379) foi pioneiro na crítica ao sistema do Código Civil de 1916 que denominava os deficientes intelectuais de "loucos" e concedia a todos o mesmo tratamento, enquanto absolutamente incapazes.

Em contraposição, a Constituição Federal de 1988 representou um grande avanço na temática da defesa dos direitos das pessoas com deficiência, efetivando o reconhecimento dos seus direitos humanos. 


\begin{abstract}
A Carta de 1988 institucionaliza a instauração de um regime político democrático no Brasil. Introduz também indiscutível avanço na consolidação legislativa das garantias e direitos fundamentais e na proteção de setores vulneráveis da sociedade brasileira. A partir dela, os direitos humanos ganham relevo extraordinário, situando-se a Carta de 1988 como o documento mais abrangente e pormenorizado sobre direitos humanos jamais adotado no Brasil (PIOVESAN, 2010, p. 24).
\end{abstract}

Por sua vez, o Código Civil de 2002 iniciou a sua tramitação no Congresso Nacional em junho de 1975, sendo que durante esse longo processo até a sua sanção no dia 10 de janeiro de 2002, a legislação brasileira passou por intensas transformações. Nesse período, a mudança mais importante foi a promulgação da Constituição Federal de 1988, cujos valores foram refletidos na legislação civil (ANDRADE; SILVA, 2015, p. 1354).

Apesar de todo esse panorama principiológico, voltado para a proteção da pessoa humana, percebe-se que o Código Civil de 2002 não representou um grande avanço na esfera da proteção da pessoa com deficiência intelectual, visto que a longa tramitação no Congresso Nacional fez com que a legislação civil conservasse vestígios de um Código consolidado em valores presentes no século XX.

Faz-se mister mencionar que o único avanço do Código Civil de 2002 em relação ao seu antecessor, nessa temática, foi o abandono das expressões arcaicas e imprecisas do ponto de vista técnico que vigoravam na legislação anterior, a qual estabelecia a incapacidade absoluta dos "loucos de todo o gênero" e dos "surdos-mudos, que não puderem exprimir a sua vontade", presentes no artigo $5^{\circ}$, II e III, respectivamente. Como mencionado anteriormente, no Código Civil de 1916 todos os deficientes intelectuais, então denominados de "loucos de todo o gênero", eram considerados absolutamente incapazes para a prática dos atos da vida civil, não sendo levado em consideração o grau de deficiência. Por sua vez, percebe-se que no Código Civil de 2002 há um tratamento diferenciado de acordo com o grau de discernimento.

Por esse motivo, torna-se imperioso o estudo da Convenção sobre os Direitos das Pessoas com Deficiência e, consequentemente, do Estatuto da Pessoa com Deficiência, os quais promoveram significativas alterações na teoria das incapacidades e nos institutos da interdição e da curatela.

A Convenção e o seu Protocolo facultativo foram assinados no dia 30 de março de 2007 em Nova York, sendo que foram aprovados no Brasil pelo Congresso Nacional por meio do Decreto Legislativo $n^{\circ} 186$ de 2008 e promulgados pelo Decreto $n^{\circ} 6.949$ de 25 de agosto de 2009. Esse documento representou uma " [...] resposta da comunidade internacional à longa 
história de discriminação, exclusão e desumanização das pessoas com deficiência" (PIOVESAN, 2010, p. 224).

Logo, cumpre evocar o artigo $1^{\circ}$, alínea $a$, da Convenção, o qual estabelece que o seu propósito é “[...] promover, proteger e assegurar o exercício pleno e equitativo de todos os direitos humanos e liberdades fundamentais por todas as pessoas com deficiência e promover o respeito pela sua dignidade inerente". A partir desse enunciado é possível notar que, em relação à proteção dos direitos humanos, o documento abrange tanto o aspecto repressivo, representado pela proibição da discriminação; quanto o promocional, referente à promoção da igualdade (PIOVESAN, 2010, p. 226).

Por sua vez, a alínea seguinte do mesmo dispositivo legal, traz um conceito inovador de deficiência, como sendo uma restrição “[...] de longo prazo de natureza física, mental, intelectual ou sensorial, os quais, em interação com diversas barreiras, podem obstruir sua participação plena e efetiva na sociedade em igualdades de condições com as demais pessoas". A grande conquista representada por esse artigo está relacionada ao reconhecimento do modelo social de deficiência, havendo uma mudança de paradigma (VITTORATI; HERNANDEZ, 2014, p. 254), ou seja, a Convenção admite que o meio social e econômico podem figurar como causa ou condição de agravamento da deficiência (PIOVESAN, 2010, p. 225).

Já no artigo $2^{\circ}$ está presente o conceito de discriminação, o qual é abrangente, incluindo diversas formas de discriminação. Uma questão relevante diz respeito à parte final do dispositivo legal que traz o dever para os Estados-partes de realizarem medidas para efetivar os direitos previstos na Convenção, sendo que a sua omissão é considerada um ato discriminatório (PIOVESAN, 2010, p. 225).

$\mathrm{O}$ artigo 12.2 dispõe que a pessoa com deficiência possui capacidade legal nas mesmas condições das demais em todos os aspectos da vida. Sobre esse assunto, Byrnes et al (2007, p. 89) leciona que:

Imagine having your capacity to make decisions, sign contracts, vote, defend your rights in court or choose medical treatments taken away simply because you have a disability. For many persons with disabilities, this is a fact of life, and the consequences can be grave. When individuals lack the legal capacity to act, they are not only robbed of their right to equal recognition before the law, they are also robbed of their ability to defend and enjoy other human rights. Guardians and tutors acting on behalf of persons with disabilities sometimes fail to act in the interests of 
the individual they are representing; worse, they sometimes abuse their positions of authority, violating the rights of others ${ }^{3}$.

Por tais razões, a Convenção assegura à pessoa com deficiência o direito de possuir ou herdar bens, de controlar as suas finanças, de ter acesso ao crédito financeiro (artigo 12.5); o direito de efetivo acesso à justiça, participando direta ou indiretamente do processo, inclusive como testemunha (artigo 13.1); o direito de escolher o local de sua residência e com quem irá morar (artigo 19, a); o direito de casar-se e decidir sobre o número de filhos (artigo 23.1); o direito de votar e ser votado (artigo 29, a), dentre outros.

Contudo, apesar do reconhecimento da capacidade legal das pessoas com deficiência, a Convenção também se preocupou com o efetivo exercício dessa capacidade, ou seja, com a plena participação da pessoa na vida social. Assim, introduziu o instituto da tomada de decisão apoiada. Segundo Byrnes et al (2007, p. 89):

The Convention recognizes that some persons with disabilities require assistance to exercise this capacity, so States must do what they can to support those individuals and introduce safeguards against abuse of that support. Support could take the form of one trusted person or a network of people; it might be necessary occasionally or all the time ${ }^{4}$.

Salienta-se que, uma vez aprovado o Tratado Internacional, é indispensável a sua incorporação no ordenamento jurídico interno, sendo que, no Brasil, esse processo dependerá do conteúdo expresso pelo tratado. No que tange aos tratados internacionais de direitos humanos, a Emenda Constitucional $n^{\circ} 45$, de 8 de dezembro de 2004, inseriu o $\S 3^{\circ}$ no artigo $5^{\circ}$, o qual dispõe que "os tratados e convenções internacionais sobre direitos humanos que forem aprovados, em cada Casa do Congresso Nacional, em dois turnos, por três quintos dos votos dos respectivos membros, serão equivalentes às emendas constitucionais".

Sendo assim, a Convenção sobre os Direitos das Pessoas com Deficiência e seu Protocolo Facultativo, foi o primeiro e, até o momento, o único tratado internacional de

\footnotetext{
${ }^{3}$ Tradução nossa: Imagine ter sua capacidade de tomar decisões, assinar contratos, votar, defender seus direitos no tribunal ou escolher um tratamento médico retirados, simplesmente porque você tem deficiência. Para muitas pessoas com deficiência, esse é um fato inevitável e as consequências podem ser graves. Quando aos indivíduos falta capacidade legal de agir, deles não é roubado apenas o direito de reconhecimento igual diante da lei, deles é roubado também sua capacidade de defender e usufruir de outros direitos humanos. Guardiões e tutores responsáveis por pessoas com deficiência, algumas vezes falham ao defender os direitos daqueles que eles estão representando; pior, eles, algumas vezes, abusam de suas posições de autoridade, violando os direitos de outros.

${ }^{4}$ Tradução nossa: A Convenção reconhece que algumas pessoas com deficiência precisam de assistência para exercitar essa capacidade, então os Estados devem fazer o possível para ajudar esses indivíduos e introduzir defesa contra os abusos a esse suporte. O suporte deve ser dado por uma pessoa confiável ou uma rede de pessoas; ele talvez seja necessário ocasionalmente ou em tempo integral.
} 
direitos humanos a ser aprovado de acordo com o rito previsto na Constituição e, portanto, possui status de Emenda Constitucional (VITTORATI; HERNANDEZ, 2014, p. 247).

Dessa forma, percebe-se que, apesar da Convenção ter representado uma grande conquista na luta pela proteção dos direitos das pessoas com deficiência, poucas atitudes foram realizadas no Brasil para efetivar esses direitos. Isso justifica-se em decorrência da cultura brasileira de não conceder a devida eficácia aos tratados internacionais, sendo necessária, muitas vezes, a promulgação de uma lei infraconstitucional, a fim de realizar os direitos previstos em uma norma com status de Emenda Constitucional ${ }^{5}$.

Diante disso, a Lei 13.146 (Lei Brasileira de Inclusão da Pessoa com Deficiência), também conhecida como Estatuto da Pessoa com Deficiência, foi decretada e sancionada pelo Congresso Nacional no dia 06 de julho de 2015 e entrou em vigor após 180 dias de sua publicação oficial, ou seja, desde janeiro de 2016 as modificações trazidas pela Lei estão vigendo. Na realidade, o Estatuto da Pessoa com Deficiência tem como base a Convenção sobre os Direitos das Pessoas com Deficiência que já estava incorporada ao ordenamento jurídico brasileiro e, portanto, foi editado como forma de regulamentá-la.

Assim, ressalta-se que ambos os diplomas legais tem como base a ideia de que a deficiência não afeta a plena capacidade civil da pessoa, prevista de forma expressa no artigo $6^{\circ}$, da Lei 13.146/2015, o qual dispõe que as pessoas com deficiência podem, inclusive: a) casar-se e constituir união estável; b) exercer direitos sexuais e reprodutivos; c) exercer o direito de decidir sobre o número de filhos e de ter acesso a informações adequadas sobre reprodução e planejamento familiar; d) conservar sua fertilidade, sendo vedada a esterilização compulsória; e) exercer o direito à família e à convivência familiar e comunitária; e f) exercer o direito à guarda, à tutela, à curatela e à adoção, como adotante ou adotando, em igualdade de oportunidades com as demais pessoas.

Como se pode depreender, a intenção do Estatuto da Pessoa com Deficiência foi realizar uma desconstrução ideológica de que a deficiência é sinônimo de incapacidade, isto é, a pessoa com deficiência passa a ser considerada legalmente capaz, ainda que para atuar na vida social, ela utilize institutos protetivos, como a curatela e a tomada de decisão apoiada.

\footnotetext{
${ }^{5}$ Uma pesquisa realizada por Alencar $(2014$, p. 62) teve como base 67 indivíduos, residentes em Ceilândia no Distrito Federal, cujos legitimados requereram a interdição no período de $1^{\circ}$ de junho de 2010 a 29 de junho de 2013. Uma das conclusões desse estudo foi que, dentre os processos analisados, $96 \%$ resultaram na interdição total, sendo que os $4 \%$ restantes obtiveram resultado diferente, em decorrência da extinção do processo por morte do interditando (ALENCAR, 2014, p. 82). Logo, nota-se que a opção pela interdição total continua sendo uma realidade no Brasil, apesar de existir a possibilidade de utilizar a interdição parcial.
} 
O Estatuto da Pessoa com Deficiência é capaz de projetar os seus efeitos por diversos ramos do direito, dentre eles está o direito civil. Dessa forma, salienta-se que os dispositivos legais mencionados acima devem ser lidos em conjunto com os artigos $3^{\circ}$ e $4^{\circ}$, do Código Civil de 2002, os quais foram alterados pelo artigo 114, da Lei 13.146/2015, havendo uma modificação substancial na teoria da incapacidade.

\section{TRANSFORMAÇÕES PROMOVIDAS PELO ESTATUTO DA PESSOA COM DEFICIÊNCIA NA TEORIA DAS INCAPACIDADES}

O Direito tem como função regular a vida em sociedade, sendo que esta é composta por pessoas que são sujeitos de direito (VENOSA, 2013, p. 127). Atrelada ao conceito de pessoa está a ideia de personalidade jurídica, a qual pode ser entendida como “[...] a soma de caracteres corpóreos e incorpóreos da pessoa natural ou jurídica, ou seja, a soma de aptidões da pessoa" (TARTUCE, 2014, p. 118). No presente estudo, enfocar-se-á a ideia de personalidade da pessoa natural que corresponde ao ser humano com vida, o qual pode assumir obrigações e titularizar direitos.

Nesse contexto, a capacidade jurídica aparece como medida da personalidade e é conceituada, em sentido amplo, como sendo "[...] a aptidão da pessoa para exercer direitos e assumir deveres na órbita civil (art. $1^{\circ}$ do CC)" (TARTUCE, 2014, p. 127). Desse modo, o vigente Código Civil dispõe no seu artigo $1^{\circ}$ que "toda pessoa é capaz de direitos e deveres na ordem civil”. Sobre esse assunto, Maria Helena Diniz (2011, p. 167) leciona que essa aptidão para adquirir direitos e contrair deveres é chamada de capacidade de gozo ou de direito, a qual não pode ser negada ao indivíduo, sob pena de lhe retirar a sua qualidade de pessoa.

Todavia, existe também a capacidade de fato ou de exercício que é a aptidão para praticar pessoalmente os atos da vida civil (FARIAS; ROSENVALD, 2010, p. 248), sendo que nem todas as pessoas a possuem, devendo-se levar em consideração diversos aspectos referentes à idade e ao estado de saúde da pessoa. Essa capacidade admite variação e gradação e, por esse motivo, o Código Civil de 2002 classifica as pessoas em plenamente capazes, absolutamente incapazes e relativamente incapazes.

Logo, aquele que possui capacidade de direito e de fato é detentor de uma capacidade plena, isso significa que o titular do direito pode atuar no plano fático sozinho, sem o auxílio de terceiros; enquanto que quem é detentor apenas da capacidade de direito possui uma 
capacidade limitada. Por conseguinte, a incapacidade é “[...] a restrição legal ao exercício dos atos da vida civil, devendo ser sempre encarada estritamente, considerando-se o princípio de que 'a capacidade é a regra e a incapacidade a exceção"” (DINIZ, 2011, p. 168).

Conforme mencionado anteriormente, a capacidade de fato é a aptidão para que a pessoa possa exercer pessoalmente os atos da vida civil. No tocante à incapacidade, o Código Civil distinguiu as pessoas absolutamente incapazes (artigo $3^{\circ}$ ) das pessoas relativamente incapazes (artigo $4^{\circ}$ ), de forma a estabelecer algumas hipóteses de falta de capacidade jurídica plena, criando, com isso, uma gradação no exercício da capacidade de fato (FARIAS; ROSENVALD, 2010, p. 252).

Cumpre observar que com o advento da Lei 13.146/2015, que instituiu o Estatuto da Pessoa com Deficiência, os artigos $3^{\circ}$ e $4^{\circ}$ do Código Civil foram profundamente alterados, de modo que foi criada uma nova teoria da incapacidade no Direito Civil Brasileiro. Estas modificações justificam-se em decorrência da ideia de que a pessoa com deficiência tem capacidade legal, conforme dispõe o artigo 84 do referido diploma legal. Assim, é importante compreender as mudanças trazidas pela Lei 13.146/2015 e as consequências provocadas por elas no que tange às pessoas consideradas absolutamente e relativamente incapazes.

Os absolutamente incapazes são “[...] aqueles que não possuem qualquer capacidade de agir, sendo irrelevante, do ponto de vista jurídico, a sua manifestação de vontade [...] por isso, precisam estar representados por terceira pessoa (o chamado representante legal)" (FARIAS; ROSENVALD, 2010, p. 254).

Nota-se que a Lei 13.146/2015 revogou os três incisos do artigo $3^{\circ}$, do Código Civil e ainda alterou o caput do dispositivo legal, passando a estabelecer uma única hipótese de incapacidade absoluta que é a das pessoas menores de 16 anos. Desse modo, "podemos dizer, já de imediato, que houve uma verdadeira revolução na teoria das incapacidades, praticada pelo citado Estatuto" (TARTUCE, 2016a, p. 129, grifos do autor). Diante do exposto, não existe mais no ordenamento jurídico brasileiro pessoa maior de idade que seja absolutamente incapaz e, consequentemente, não existe mais ação de interdição total no sistema civil. Com isso, todas as pessoas com deficiência que estavam presentes no artigo $3^{\circ}$, do Código Civil, passam a ser, em regra, plenamente capazes.

Por sua vez, os relativamente incapazes são aqueles que o sistema jurídico não ignora a sua manifestação de vontade, mas é necessário que eles sejam assistidos para que ela seja válida. Dessa forma, eles necessitam de proteção jurídica, mas em grau inferior quando comparados aos absolutamente incapazes (FARIAS; ROSENVALD, 2010, p. 257). 
Não houve alteração no inciso I e no inciso IV, ambos do artigo $4^{\circ}$, do Código Civil, continuando a estabelecer a incapacidade relativa dos maiores de 16 anos e menores de 18 anos, bem como a dos pródigos.

Contudo, o inciso II previa três hipóteses de incapacidade relativa, sendo que a última delas foi retirada pela Lei 13.146/2015, referente às pessoas com deficiência intelectual. Já o artigo $4^{\circ}$, III, mencionava os excepcionais sem desenvolvimento mental completo, como é o caso dos portadores de síndrome de Down. Com isso, os ébrios habituais, os viciados em tóxicos e os excepcionais são considerados plenamente capazes, sendo que somente em situações excepcionais serão tidos como relativamente incapazes, enquadrados no novo artigo $4^{\circ}$, III (TARTUCE, 2016a, p. 136).

Por fim, o artigo $4^{\circ}$, III passou a tratar da antiga previsão do artigo $3^{\circ}$, III, ampliando as hipóteses de incapacidade relativa, abarcando as pessoas que, mesmo por causa transitória, não puderem exprimir sua vontade. Nesse aspecto, é importante apontar um equívoco cometido pelo Estatuto da Pessoa com Deficiência, uma vez que não é possível considerar como relativamente incapaz uma pessoa que não tem como exprimir a sua vontade, a exemplo da pessoa que está em coma, sendo necessário que ela seja representada por um curador.

Percebe-se que de acordo com o artigo $6^{\circ}$, do Estatuto, a deficiência não afeta a plena capacidade civil da pessoa e, diante disso, foi necessário modificar a teoria das incapacidades do Código Civil, retirando-se da legislação todas as hipóteses de maiores absolutamente incapazes. Contudo, não é possível deixar de considerar que as pessoas com deficiência intelectual continuam a ser vulneráveis e, por esse motivo, em determinadas situações, ainda que a pessoa seja plenamente capaz, ela necessitará utilizar institutos protetivos como a curatela e a tomada de decisão apoiada, sendo que este último será objeto de análise do próximo capítulo.

\section{A VULNERABILIDADE SOCIAL E O INSTITUTO DA TOMADA DE DECISÃO APOIADA}

O reconhecimento da capacidade plena das pessoas com deficiência intelectual atua como uma desconstrução ideológica do conceito de incapacidade civil. Associada a essa visão desestigmatizante, é importante considerar que deve ser aplicada às pessoas com deficiência 
intelectual a noção de vulnerabilidade, uma vez que elas continuam necessitando de um tratamento diferenciado.

Nesse contexto, faz-se relevante ressaltar que não são apenas os eventos de natureza econômica que vulnerabilizam as pessoas, isto é, existem diversas variáveis que contribuem para esse fenômeno, não podendo ser reduzido à falta ou à insuficiência de condições para satisfazer as necessidades básicas (ALMEIDA, 2005, p. 2). Desse modo, surge o conceito de vulnerabilidade social, o qual apresenta um caráter multidimensional, visto que considera inúmeros fatores para a sua definição, levando em conta as diversas formas e graus de intensidade do bem estar das pessoas, grupos e comunidades (DEFENSORIA PÚBLICA DO ESTADO DE SÃO PAULO, p. 2).

Segundo Laura Maria Pedrosa de Almeida (2005, p. 2), a vulnerabilidade social envolve fatores como:

[...] a fragilização dos vínculos afetivo-relacionais e de pertencimento social (discriminações etárias, étnicas, de gênero ou por deficiência...), ou vinculados à violência, ao território, à representação política dentre outros, também afetam as pessoas.

Com isso, são excluídas todas as pessoas que perderam ou nem conseguiram ter um vínculo com o meio social, tais como pessoas idosas, com deficiência, desempregados de longa duração, minorias étnicas, etc. Consequentemente, esses grupos sociais são estigmatizados, especialmente quando encontram-se em situação de pobreza, sendo que essa circunstância, quando analisada em conjunto com os obstáculos enfrentados para ter acesso à saúde, educação, emprego, lazer e cultura, fragiliza ainda mais as pessoas idosas e as pessoas com deficiência, potencializando as suas vulnerabilidades (BELEZA et al, 2009, p. 7).

Diante do exposto, é importante retomar o conceito de pessoa com deficiência presente tanto no artigo $1^{\circ}$, da Convenção sobre os Direitos das Pessoas com Deficiência, quanto no artigo $2^{\circ}$, do Estatuto da Pessoa com Deficiência, os quais adotam o modelo social de deficiência, o qual a transformou em "[...] um conceito complexo que reconhece o corpo com lesão, mas que também denuncia a estrutura social que oprime a pessoa deficiente" (DINIZ, 2012, p. 10).

Esse é um campo pouco explorado no Brasil não apenas porque a deficiência ainda não se libertou da autoridade biomédica, com poucos cientistas sociais dedicando-se ao tema, mas principalmente porque a deficiência ainda é considerada uma tragédia pessoal, e não como uma questão de justiça social. O desafio está em afirmar a deficiência como um estilo de vida, e também em reconhecer a legitimidade de 
ações distributivas e de reparação da desigualdade, bem como a necessidade de cuidados biomédicos (DINIZ, 2012, p. 11).

Por esse motivo, é de grande importância o reconhecimento do modelo social de deficiência pela Convenção Internacional e pela Lei 13.146/2015, uma vez que de acordo com o Censo de 2010, realizado pelo Instituto Brasileiro de Geografia e Estatística (IBGE, 2010), 23,9\% da população brasileira apresenta algum tipo de deficiência (visual, auditiva, motora, mental ou intelectual), percentagem esta que representa 45.606 .048 brasileiros, dos quais $1,40 \%$ possuem deficiência mental ou intelectual.

Em razão da expressividade desse número, o novo conceito de deficiência deve ser utilizado como forma de exigir uma prestação do Estado na proteção social das pessoas com deficiência, incluindo-as no meio social (SANTOS, 2008, p. 516) e, consequentemente, por meio dessas políticas de inclusão e do reconhecimento social das diferenças será possível reduzir gradativamente a vulnerabilidade social dessas pessoas.

Conforme já explicado, tanto a Convenção sobre os Direitos das Pessoas com Deficiência quanto o Estatuto reconhecem que algumas pessoas com deficiência precisam de assistência para exercitar a sua capacidade e, por esse motivo, foi introduzido o instituto da tomada de decisão apoiada no direito brasileiro. Desse modo, Byrnes et al (2007, p. 89-90) explica que:

\begin{abstract}
With supported decision-making, the presumption is always in favour of the person with a disability who will be affected by the decision. The individual is the decision maker; the support person(s) explain(s) the issues, when necessary, and interpret(s) the signs and preferences of the individual. Even when an individual with a disability requires total support, the support person(s) should enable the individual to exercise his/her legal capacity to the greatest extent possible, according to the wishes of the individual. This distinguishes supported decision-making from substituted decision-making, such as advance directives and legal mentors/friends, where the guardian or tutor has court-authorized power to make decisions on behalf of the indi- vidual without necessarily having to demonstrate that those decisions are in the individual's best interests or according to his/her wishes. Paragraph 4 of article 12 calls for safeguards to be put in place to protect against abuse of these support mechanisms ${ }^{6}$.
\end{abstract}

\footnotetext{
${ }^{6}$ Tradução nossa: Com a tomada de decisão apoiada, a presunção é sempre em favor da pessoa com deficiência que será afetada pela decisão. O indivíduo é o tomador da decisão; a pessoa que o assiste explica os problemas, quando necessário, e interpreta os sinais e preferências do indivíduo. Até mesmo quando um indivíduo com deficiência requer suporte total, a pessoa deveria permitir o indivíduo de exercitar sua capacidade legal o máximo possível, de acordo com a sua vontade. Isso diferencia a tomada de decisão apoiada da tomada de decisão substitutiva, tal como autorizações e mentores/amigos legais, em que o guardião ou tutor tem poderes autorizados pelo tribunal para tomar decisões em favor do indivíduo sem necessariamente ter demonstrado que tais decisões são do interesse do indivíduo ou de acordo com a vontade dele. Parágrafo $4^{\circ}$ do artigo 12 diz que salvaguardas devem ser colocadas para proteger contra abuso desses mecanismos de apoio.
} 
Assim como a tomada de decisão apoiada, existe no direito estrangeiro outros institutos que se diferenciam da curatela. Essas medidas podem apresentar-se por meio da criação de novos modelos que excluem a curatela do ordenamento jurídico, como no caso da austríaca Sachwalterschaft e da alemã Betreuung, e também por meio da criação de modelos alternativos à curatela sem a exclusão desta. Nesse último caso, é possível que o novo instituto provoque o desuso da curatela, como ocorreu com a criação do "administrador" belga e da figura do amministrazione di sostegno italiana, ou ele poderá simplesmente conviver com a curatela, como na sauvegarde de justice francesa (VÍTOR apud REQUIÃO, 2015).

O Estatuto da Pessoa com Deficiência, que modificou o Código Civil para incluir o artigo 1.783-A, optou pela convivência entre a curatela e a tomada de decisão apoiada, sendo, inclusive, aplicada à este instituto as disposições referentes à prestação de contas na curatela, no que couber, conforme $\S 11$ do referido dispositivo legal. Todavia, somente o tempo mostrará se na realidade brasileira a tomada de decisão apoiada acarretará no desuso da curatela (REQUIÃO, 2015).

Esse instituto tem como objetivo auxiliar "[...] a pessoa com deficiência para a celebração de atos mais complexos, caso dos contratos" (TARTUCE, 2016b, p. 670). É uma forma de impedir que abusos e desrespeitos sejam praticados, inclusive em nome no melhor interesse das pessoas com deficiência.

Iniciando a sua análise pelo caput do artigo 1.783-A, este estabelece que:

Art. 1.783-A. A tomada de decisão apoiada é o processo pelo qual a pessoa com deficiência elege pelo menos 2 (duas) pessoas idôneas, com as quais mantenha vínculos e que gozem de sua confiança, para prestar-lhe apoio na tomada de decisão sobre atos da vida civil, fornecendo-lhes os elementos e informações necessários para que possa exercer sua capacidade.

É importante observar que a tomada de decisão apoiada não está necessariamente relacionada à pessoa com transtorno mental, podendo ser requerida por qualquer indivíduo que se adeque ao conceito de deficiente presente no Estatuto (REQUIÃO, 2015). Ademais, é possível perceber pela redação do dispositivo legal acima mencionado que esse instituto protege:

[...] o espaço de escolha do portador de transtorno mental, que pode constituir em torno de si uma rede de sujeitos baseada na confiança que neles tem, para lhe 
auxiliar nos atos da vida. Justamente o oposto do que podia antes acontecer (e, formalmente, ainda pode!), em algumas situações de curatela fixadas à revelia e contra os interesses do portador de transtornos mentais (REQUIÃO, 2015).

Por sua vez, o $\S 1^{\circ}$, dispõe que para formular o pedido de tomada de decisão apoiada, a pessoa com deficiência e os apoiadores devem apresentar um termo em que conste os limites do apoio a ser oferecido e os compromissos dos apoiadores. Ainda deve constar o prazo de vigência do acordo e o respeito à vontade, aos direitos e aos interesses da pessoa que devem apoiar. Nota-se que o respeito à autonomia do apoiado também está presente no termo em que se faz o pedido de tomada de decisão apoiada (REQUIÃO, 2015).

No direito comparado, o Código Civil italiano estabelece que a amministrazione di sostegno pode ser por prazo indeterminado, enquanto que o Código Civil francês diz que a sauvegarde de justice não pode ser superior ao período de 1 ano, sendo renovável por uma vez (REQUIÃO, 2015). Já o Código Civil brasileiro dispôs que deve estar presente no termo o prazo de vigência, todavia, não determinou um período máximo, nem a possibilidade de renovação.

Conforme o $\S 2^{\circ}$, “o pedido de tomada de decisão apoiada será requerido pela pessoa a ser apoiada, com indicação expressa das pessoas aptas a prestarem o apoio previsto no caput deste artigo". Pela redação desse dispositivo, percebe-se que a legitimidade ativa para requerer a tomada de decisão apoiada é somente do sujeito que a utilizará, reforçando novamente a autonomia da pessoa com deficiência, a qual terá apoiadores porque os quis e não porque lhe foram designados (REQUIÃO, 2015).

Trata-se, claramente, de um procedimento judicial, pois o $\S 3^{\circ}$ determina que "antes de se pronunciar sobre o pedido de tomada de decisão apoiada, o juiz, assistido por equipe multidisciplinar, após oitiva do Ministério Público, ouvirá pessoalmente o requerente e as pessoas que lhe prestarão apoio" (TARTUCE, 2016b, p. 671).

Caso a decisão tomada por pessoa apoiada esteja dentro dos limites do apoio acordado, ela será válida e terá efeitos sobre terceiros, nos termos do $§ 4^{\circ}$ do artigo $1.783-\mathrm{A}$, do Código Civil. Sobre esse assunto, Tartuce (2016b, p. 671, grifos do autor) explica que:

Assim, presente a categoria, desaparece toda aquela discussão aqui exposta a respeito da validade e eficácia dos atos praticados por incapazes, como vendas de imóveis, frente a terceiros de boa-fé. Em havendo uma tomada de decisão apoiada, não se cogitará mais sua nulidade absoluta, nulidade relativa ou ineficácia [...]. 
Complementando, o $\S 5^{\circ}$ dispõe que "terceiro com quem a pessoa apoiada mantenha relação negocial pode solicitar que os apoiadores contra-assinem o contrato ou acordo, especificando, por escrito, sua função em relação ao apoiado". Essa previsão está relacionada ao princípio da boa-fé objetiva e busca eliminar dúvidas acerca da idoneidade jurídica do ato praticado (TARTUCE, 2016b, p. 671).

Contudo, havendo um negócio jurídico que "possa trazer risco ou prejuízo relevante, havendo divergência de opiniões entre a pessoa apoiada e um dos apoiadores, deverá o juiz, ouvido o Ministério Público, decidir sobre a questão", conforme $\S 6^{\circ}$ do artigo 1.783-A. Segundo Tartuce (2016b, p. 671), poderá o juiz, eventualmente, suprir a vontade da parte discordante.

Além disso, Requião (2015) chama atenção para o fato de que o juiz somente decidirá a controvérsia se o negócio puder trazer risco ou prejuízo relevante. Assim, surge a dúvida sobre o que acontece quando a divergência ocorrer em negócio de menor monta. Para o autor, a resposta está presente de forma implícita no prórpio parágrafo $6^{\circ}$ e de forma sistemática no Estatuto da Pessoa com Deficiência, visto que o dispositivo legal foi expresso ao falar em risco ou prejuízo relevante e, portanto, nos demais casos prevalecerá a escolha do apoiado sobre a dos apoiadores.

Isso ocorre em decorrência do privilégio da autonomia do apoiado e para que não se deixe de considerer que a tomada de decisão apoiada somente se constitui a partir do interesse do apoiado. Contudo, nesse caso, o apoiador poderá registrar a sua opinião contrária a do apoiado, a fim de que, posteriormente, ele não seja acusado de ter atuado de forma negligente (REQUIÃO, 2015).

Já o $\S 7^{\circ}$ do artigo 1.783-A estabelece que "se o apoiador agir com negligência, exercer pressão indevida ou não adimplir as obrigações assumidas, poderá a pessoa apoiada ou qualquer pessoa apresentar denúncia ao Ministério Público ou ao juiz”. Em relação a isso, Tartuce (2016b, p. 671) entende que é possível cogitar a invalidade do ato se ele já tiver sido praticado.

Caso seja procedente a denúncia, o juiz destituirá o apoiador e nomeará outro, se for do interesse da pessoa apoiada, devendo esta sempre ser ouvida (artigo 1.783-A, $\S 8^{\circ}$ ). Apesar da lei não especificar, Requião (2015) entende que se um dos apoiadores for destituído e o apoiado não quiser a nomeação de um novo, ocorrerá a extinção da tomada de decisão apoiada, visto que a legislação exige dois apoiadores. Salienta-se que essa extinção pode 
ocorrer a qualquer tempo por meio de solicitação da pessoa apoiada (artigo 1.783-A $\S 9^{\circ}$ ), tratando-se de direito potestativo e, portanto, não cabe ao juiz denegar esse pedido.

Também existe a possibilidade do apoiador solicitar ao juiz a exclusão da sua participação do processo de tomada de decisão apoiada, devendo ele manifestar-se sobre o assunto para que ocorra o desligamento, conforme o $\S 10$, do artigo 1.783-A. De acordo com o posicionamento de Requião (2015), essa saída do apoiador não levará à automática extinção do processo de tomada de decisão apoiada, devendo o apoiado indicar novo apoiador e, apenas se ele não quiser, ocorrerá a extinção.

Outra questão que pode surgir refere-se à capacidade do sujeito que requer a tomada de decisão apoiada. Os regimes estrangeiros que foram citados abordam essa questão de formas diferentes, o que indica que a limitação ou não da capacidade é uma escolha legislativa. No que se refere ao Brasil, Requião (2015) aponta que a tomada de decisão apoiada não parece implicar na perda da capacidade da pessoa que a requer, mas sim permite um reforço da validade dos negócios por ela realizados.

Diante do exposto, percebe-se que vários são os desafios impostos pelo Estatuto da Pessoa com Deficiência para os aplicadores e intérpretes do Direito Privado, principalmente pela falta de dispositivos legais regulando a tomada de decisão apoiada. Posto isso, é importante considerar que:

The Province of British Columbia in Canada is one of the leading jurisdictions in incorporating supported decision-making into law, policy and practice. An individual with disabilities can enter a "representation agreement" with a support network. The agreement is a sign to others, including doctors, financial institutions and service providers, that the individual has given the network the authority to assist him/her in making decisions and represent him/her in certain matters.

One of the main innovations in the legislation is that persons with more significant disabilities can enter into representation agreements with a support network simply by demonstrating "trust" in the designated supporters. A person does not need to prove legal competency under the usual criteria, such as having a demonstrated capacity to understand relevant information, appreciate consequences, act voluntarily and communicate a decision independently, in order to enter this agreement.

A number of individuals and support networks have entered representation agreements as an alternative to guardianship or other forms of substitute decisionmaking. A community-based representation agreement resource centre assists in developing and sustaining support networks by providing informa- tion, publications, workshops and advice. The centre also oversees a registry in which a 
network can post an agreement for other parties to view if required before entering a contract with the individual (BYRNES et al, 2007, p. 90) ${ }^{7}$.

Conforme explicado, a tomada de decisão apoiada não é um instituto que visa substituir a vontade da pessoa apoiada, muito pelo contrário, a ideia é a de que a pessoa com deficiência possa tomar as suas próprias decisões com o auxílio de alguém da sua confiança, elemento que é essencial nessa medida.

Em decorrência da escassez de dispositivos legais regulamentando o instituto da tomada de decisão apoiada e da tradição brasileira de interditar absolutamente os incapazes, até mesmo em situações que seriam de incapacidade relativa, é importante essa análise do direito comparado para que o judiciário se espelhe em países que já consolidaram a utilização desse instituto. Isso se justifica como forma de evitar que o artigo 1.783-A, do Código Civil, torne-se uma "regra morta", no sentido de não ser utilizada ou de ser utilizada incorretamente.

\section{CONSIDERAÇÕES FINAIS}

Ante o exposto, percebe-se que o regime das incapacidades do Código Civil teve que ser interpretado à luz da Convenção sobre os Direitos das Pessoas com Deficiência e da Lei 13.146/2015 e reorientado no sentido do reconhecimento da capacidade legal plena das pessoas com deficiência.

O fundamento para a retirada da capacidade das pessoas com deficiência intelectual sempre foi a proteção do exercício dos seus atos civis, a fim de resguardar o seu patrimônio e, assim, a vontade delas não era levada em consideração. Entretanto, a Lei 13.146/2015 altera essa ideia de modo a permitir a tutela da dignidade-liberdade das pessoas com deficiência e,

\footnotetext{
${ }^{7}$ Tradução nossa: A província britância de Columbia no Canadá é uma das jurisdições líderes no sistema de tomada de decisão apoiada, incorporando-a na política, na prática e na lei. Um indivíduo com deficiência pode entrar com um acordo de representação com uma rede de apoio. O acordo é um sinal para outros, incluindo médicos, instituições financeiras e serviço de provedores, de que o indivíduo deu à rede a autoridade de ajudá-lo a tomar decisões e representá-lo em certos assuntos.

Uma das principais inovações na legislação é que pessoas com deficiências mais significantes podem pedir acordos de representação com rede de apoio simplesmente demonstrando "confiança" nos provedores designados. Uma pessoa não precisa provar competência legal sob critérios usuais, tal como ter capacidade demonstrada de entender informação relevante, entender as consequências, agir voluntariamente e comunicar uma decisão de forma independente, para entrar nesse acordo.

Um número de indivíduos e redes de apoios entraram com acordo de representação como uma alternativa à guarda e outras formas de substituição da tomada de decisão. Um centro de pesquisa de acordo de representação fundamentado na comunidade ajuda as redes de apoio a se desenvolverem e a se manterem dando informação, publicações, oficinas e conselhos. O centro também fornece um registro no qual a rede pode postar um acordo para outros grupos visualizarem, se pedido antes de firmar um contrato com o indivíduo.
} 
com isso, a deficiência passa a ser considerada com a finalidade de inclusão e não para limitar ou impedir o exercício de direitos.

Nesse sentido, o Estatuto teve a preocupação não só de declarar a plena capacidade da pessoa com deficiência maior de 18 anos para decidir sobre casamento, sexualidade, filhos, entre outros, como também estabeleceu instrumentos para a sua proteção, como a curatela especial e a tomada de decisão apoiada.

Não é possível saber ainda se a tomada de decisão apoiada substituirá, no futuro, a curatela, mas é preciso ter em mente a importância desse instituto ao permitir que as pessoas com deficiência tomem as suas decisões com autonomia, ao mesmo tempo, em que são protegidas. Assim, como a curatela torna-se, a partir da nova sistemática, uma medida excepcional, ela apenas será utilizada se a tomada de decisão apoiada não for possível naquele caso concreto.

Desse modo, é necessária uma mudança da mentalidade da sociedade, com o objetivo de perceber que incapacidade e vulnerabilidade não são sinônimos. Assim, muito embora as pessoas com deficiência sejam plenamente capazes, permanece o processo de fragilização dos vínculos afetivo-relacionais e de pertencimento social, caracterizando a vulnerabilidade social. Em razão disso, as medidas protetivas continuam sendo necessárias, mas não nos mesmos moldes que o histórico da legislação brasileira tratou as pessoas com deficiência intelectual, devendo-se privilegiar a sua manifestação de vontade.

\section{REFERÊNCIAS}

ALENCAR, Cícero Pereira. Interdição parcial de pessoas com deficiência no Distrito Federal: entre o texto legal e o mundo real. 2014. 103 f. Monografia (Graduação em Direito) - Centro Universitário de Brasília, Distrito Federal, 2014. Disponível em: http://repositorio.uniceub.br/bitstream/235/5625/1/20966204.pdf. Acesso em 23 jan. 2016.

ALMEIDA, Laura Maria Pedrosa de. Vulnerabilidade social. Desenvolvimento Humano no Recife. Atlas Municipal, 2005. Disponível em:

http://www.recife.pe.gov.br/pr/secplanejamento/pnud2005/8.\%20Vulnerabilidade\%20Social. pdf. Acesso em: 21 abr. 2016.

ANDRADE, Fábio Siebeneichler de; SILVA, Gilberto Antonio Neves Pereira. Notas sobre as implicações do novo código de processo civil na autonomia do curatelado. Revista 
Eletrônica Direito e Política, Itajaí, v. 10, n. 2, p. 1348-1370, jan./abr. 2015. Disponível em: http://www6.univali.br/seer/index.php/rdp/article/view/7797/4435. Acesso em: 18 jan. 2016.

BELEZA, Clarissa Alliati et al. Relatório de pesquisa: vulnerabilidade social, resiliência e estratégias de resistência na condição de deficiência e da terceira idade. Fundação de Articulação e Desenvolvimento de Políticas Públicas para Pessoas com Deficiência e com Altas Habilidades no Rio Grande do Sul FADERS. Porto Alegre, 2009. Disponível em: http://www.faders.rs.gov.br/publicacoes/20. Acesso em: 21 abr. 2016.

BYRNES; Andrew et al. From exclusion to equality: realizing the rights of persons with disabilities. Handbook for parlamentarians, n. 14, UN, OHCHR, Genebra, 2007. Disponível em: http://www.ohchr.org/Documents/Publications/training14en.pdf. Acesso em: 13 jan. 2016.

DEFENSORIA PÚBLICA DO ESTADO DE SÃO PAULO. Vulnerabilidade social com ênfase ao atendimento à população em situação de rua. Disponível em: http://www.defensoria.sp.gov.br/dpesp/repositorio/0/documentos/cam/Vulnerabilidade\%20So cial.pdf. Acesso em: 21 abr. 2016.

DINIZ, Debora. O que é deficiência. São Paulo: Brasiliense, 2012. 80 p. (Coleção Primeiros Passos, 324).

DINIZ, Maria Helena. Curso de direito civil brasileiro: teoria geral do direito civil. 28. ed. São Paulo: Saraiva, 2011. v. 1.

FARIAS, Cristiano Chaves de; ROSENVALD, Nelson. Direito Civil: teoria geral. 8. ed. Rio de Janeiro: Lumen Juris, 2010. v. 1.

IBGE. Cartilha do censo demográfico de 2010: pessoas com deficiência. Brasília: SDHPR/SNPD, 2012. Disponível em:

http://www.pessoacomdeficiencia.gov.br/app/sites/default/files/publicacoes/cartilha-censo2010-pessoas-com-deficienciareduzido.pdf. Acesso em: 23 abr. 2016.

MEDEIROS, Maria Bernadette de Moraes. Interdição civil: uma exclusão oficializada?. Revista Virtual Textos e Contextos, Porto Alegre, n. 5, p. 1-21, nov. 2006. Disponível em: http://revistaseletronicas.pucrs.br/ojs/index.php/fass/article/viewFile/1021/801. Acesso em: 05 jan. 2016

MENEZES, Joyceane Bezerra de; CORREIA NETO, Jáder de Figueiredo. Interdição e curatela no novo CPC à luz da dignidade da pessoa humana e do direito civil constitucional. 
In: CONSELHO NACIONAL DE PESQUISA E PÓS-GRADUAÇÃO EM DIREITO, 23., 2014, Florianópolis, Anais eletrônicos... Florianópolis: CONPEDI, 2014, p. 369-387. Disponível em: http://www.publicadireito.com.br/artigos/?cod=029b50deea7a25c4. Acesso em: 05 jan. 2016.

MIRANDA, Pontes de. Tratado de direito privado: parte especial - direito de família: direito parental, direito protetivo. Campinas: Bookseller, 2000. Tomo 9.

PIOVESAN, Flávia. Direitos humanos e o direito constitucional internacional. 11 ed. São Paulo: Saraiva, 2010.

REQUIÃO, Maurício. Conheça a tomada de decisão apoiada, novo regime alternativo à curatela. Revista Consultor Jurídico, [S.1.], 14 set. 2015. Disponível em:

http://www.conjur.com.br/2015-set-14/direito-civil-atual-conheca-tomada-decisao-apoiadaregime-alternativo-curatela\#_ftn5. Acesso em: 21 maio 2016.

SANTOS, Fabíola Sousa dos. O trato jurídico dispensado à pessoa com transtorno mental: notas acerca da máxima eficácia à sua proteção. Domus On Line, Salvador, v. 10, p. 136157, jan./dez. 2013. Disponível em: ojs.fbb.br/ojs/index.php/domus/article/view/94. Acesso em: 04 jan. 2016.

SANTOS, Wederson Rufino dos. Pessoas com deficiência: nossa maior minoria. Physis Revista de Saúde Coletiva, Rio de Janeiro, n. 3, v. 18, p. 501-519, set. 2008. Disponível em: http://www.scielo.br/scielo.php?pid=S0103-

73312008000300008\&script=sci_abstract\&tlng=pt. Acesso em: 23 abr. 2016.

TARTUCE, Flávio. Direito Civil: lei de introdução e parte geral. 10. ed. Rio de Janeiro: Forense; São Paulo: Método, 2014. v.1. 2016a. v.1.

Direito Civil: lei de introdução e parte geral. 12. ed. Rio de Janeiro: Forense, Direito Civil: direito de família. 11. ed. Rio de Janeiro: Forense, 2016b. v. 5.

VENOSA, Sílvio de Salvo. Direito civil: parte geral. 13. ed. São Paulo: Atlas, 2013. v. 1.

VITTORATI, Luana da Silva; HERNANDEZ, Matheus de Carvalho. Convenção sobre os direitos das pessoas com deficiência: como "invisíveis" conquistaram seu espaço. Revista de Direito Internacional, Brasília, v. 11, n. 1, p. 230-262, 2014. Disponível em: http://www.publicacoesacademicas.uniceub.br/index.php/rdi/article/view/2689. Acesso em 12 jan. 2016. 